\title{
TNM staging of foregut (neuro)endocrine tumors: a consensus proposal including a grading system
}

\author{
G. Rindi • G. Klöppel • H. Alhman • M. Caplin • \\ A. Couvelard • W. W. de Herder • B. Erikssson • \\ A. Falchetti • M. Falconi • P. Komminoth • M. Körner • \\ J. M. Lopes • A-M. McNicol • O. Nilsson • A. Perren • \\ A. Scarpa $\cdot$ J-Y. Scoazec $\cdot$ B. Wiedenmann . \\ and all other Frascati Consensus Conference \\ participants
}

Received: 11 April 2006 / Accepted: 6 June 2006/ Published online: 12 September 2006

(C) Springer-Verlag 2006

\begin{abstract}
The need for standards in the management of patients with endocrine tumors of the digestive system prompted the European Neuroendocrine Tumor Society (ENETS) to organize a first Consensus Conference, which
\end{abstract}

List of the participants to the "Consensus Conference on the ENETS Guidelines for the Diagnosis and Treatment of Neuroendocrine Gastrointestinal Tumors, Part 1: Foregut Tumors" held in Frascati (Rome, Italy), November 2-5, 2005 (front Authors not listed): R. Arnold, Department of Gastroenterology, Philipps University, Marburg (Germany); W.O. Bechstein, Department of Surgery, JohannWolfgang-Goethe-Universität, Frankfurt (Germany); G. Cadiot, Department of Hepatology and Gastroenterology, C.H.U. Bichat-B. Claude Bernard University, Paris (France); E. Christ, Department of Endocrinology, Inselspital, Bern (Switzerland); D. Chung, Department of Gastroenterology, Massachussetts General Hospital, Boston, MA (USA); G. Delle Fave, Department of Digestive and Liver Disease, Ospedale S. Andrea, Rome (Italy); D. Ferone, Department of Endocrinology, Genoa University, Genoa (Italy); P. Goretzki, Department of Surgery, Städtisches Klinikum Neuss, Lukas Hospital, Neuss (Germany); D. Gross, Department of Endocrinology and Metabolism, Hadassah University, Jerusalem (Israel); D. Hochhauser, Department of Oncology, Royal Free University, London (United Kingdom); R. Hyrdel, Department of Internal Medicine, Martin University, Martin (Slovakia); R. Jensen, Department of Cell Biology, National Institute of Health, Bethesda, MD (USA); G. Kaltsas, Department of Endocrinology and Metabolism, Genimatas Hospital, Athens (Greece); F. Keletimur, Department of Endocrinology, Erciyes University, Kayseri (Turkey); R. Kianmanesh, Department of Surgery, UFR Bichat-Beaujon-Louis Mourier Hospital, Colombes (France); W. Knapp, Department of Nuclear Medicine, Medizinische Hochschule Hannover, Hannover (Germany); U.P. Knigge, Department of Surgery, Rigshospitalet Blegdamsuej Hospital, Copenhagen (Denmark); B. Kos-Kuda, Department of Endocrinology, Slaska University, Zabrze (Poland); L. Kvols, Department of Oncology, South Florida University, Tampa, FL (USA); D. Kwekkeboom, Department of Nuclear Medicine, Erasmus MC University, Rotterdam (the Netherlands); V. Lewington, Department of Radiology, Royal Marsden Hospital, Sutton (United Kingdom); R. Manfredi, Department of Radiology, Istituto di Radiologia, Policlinico GB,
Verona (Italy); E. Mitry, Department of Hepatology and Gastroenterology, CHV A Pare Hospital, Boulogne (France); B. Niederle, Department of Surgery, Wien University, Vienna (Austria); G. Nikou, Department of Propaedeutic Internal Medicine, Laiko Hospital, Athens (Greece); K. Öberg, Department of Endocrinology, University Hospital, Uppsala (Sweden); J. O'Connor, Department of Oncology, Alexander Fleming Institute, Buenos Aires (Argentina); D. O'Toole, Department of Gastroenterology, Beaujon Hospital, Clichy (France); S. Pauwels, Department of Nuclear Medicine, Catholique de Louvain University, Brussels (Belgium); M. Pavel, Department of Endocrinology, Erlangen University, Erlangen (Germany); U. Plöckinger, Department of Hepatology and Gastroenterology, Charité Universitäts Medizin, Berlin (Germany); J. Ramage, Department of Gastroenterology, North Hampshire Hospital, Hampshire (United Kingdom); J. Ricke, Department of Radiology, Charité Universitäts Medizin, Berlin (Germany); P. Ruszniewski, Department of Gastorenterology, Beaujon Hospital, Clichy (France); R. Salazar, Department of Oncology, Institut Català d'Oncologia, Barcelona (Spain); A. Sauvanet, Department of Surgery, Beaujon Hospital, Clichy (France); M.I. Sevilla Garcia, Department of Oncology, Virgen de la Victoria Hospital, Malaga (Spain); T. Steinmüller, Department of Surgery, Vivantes Humboldt Hospital, Berlin (Germany); A. Sundin, Department of Radiology, Uppsala University, Uppsala (Sweden); B. Taal, Department of Oncology, Netherlands Cancer Centre, Amsterdam (the Netherlands); E. Van Cutsem, Department of Gastroenterology, Gasthuisberg University, Leuven (Belgium); M.P. Vullierme, Department of Gastroenterology, Beaujon Hospital, Clichy (France); S. Wildi, Department of Surgery, Zürich Hospital, Zürich, Switzerland; J.C. Yao, Department of Oncology, University of Texas, Houston, TX (USA).

\section{G. Rindi $(\square)$}

Dipartimento di Patologia e, Medicina di Laboratorio, Sezione di Anatomia Patologica, Università di Parma, Via Gramsci, 14, 43100 Parma, Italy e-mail: guido.rindi@unipr.it

G. Klöppel

Department of Pathology, University of Kiel,

Kiel, Germany 
was held in Frascati (Rome) and was based on the recently published ENETS guidelines on the diagnosis and treatment of digestive neuroendocrine tumors (NET). Here, we report the tumor-node-metastasis proposal for foregut NETs of the stomach, duodenum, and pancreas that was designed, discussed, and consensually approved at this conference. In addition, we report the proposal for a working formulation for the grading of digestive NETs based on mitotic count and Ki-67 index. This proposal, which needs to be validated, is meant to help clinicians in the stratification, treatment, and follow-up of patients.

Keywords Neuroendocrine tumors · Gut · Pancreas · Staging $\cdot$ TNM $\cdot$ Grading $\cdot$ Mitotic index $\cdot$ Ki-67 index

\section{Background}

It has been known for a long time, and was finally defined within the World Health Organization (WHO) classification of endocrine and digestive tumors, that neuroendocrine tumors (NET) arising at different anatomical sites of the digestive system represent tumor entities that differ in their biology $[5,7,9,31]$. Several recent publications focused on the application of the "new" WHO classification and proved its effectiveness, supporting the concept that the

\section{H. Alhman}

Department of Surgery, Gothenburg University,

Gothenburg, Sweden

M. Caplin

Department of Internal Medicine, Royal Free Hospital,

London, UK

\section{A. Couvelard}

Department of Pathology, Hôpital Beaujon,

Clichy, France

W. W. de Herder

Department of Internal Medicine,

Erasmus, Rotterdam,

The Netherlands

B. Erikssson

Department of Endocrinology, University Hospital,

Uppsala, Sweden

A. Falchetti

Department of Internal Medicine, University of Florence,

Florence, Italy

M. Falconi

Department of Surgery, University of Verona,

Verona, Italy

P. Komminoth

Department of Pathology, Kantosspital Baden,

Baden, Switzerland different endocrine tumor types also differ in their clinical behavior $[3,4,19,20,27,32]$.

Malignant gastroenteropancreatic NETs may be fatal, though at a significantly slower pace than their exocrine counterparts. A number of retrospective papers and epidemiological data solidly support such statements $[8,9,12$ $14,21,24,25,32]$. This peculiar clinical feature attracted the interest of pathologists very early and was the reason for the special designation of such tumors as "carcinoid" by Oberndorfer [15].

As gastroenteropancreatic NETs are rare [9, 13, 14], it is tempting to lump them together and equate all digestive "carcinoids" with the appendiceal "carcinoid," probably the best known NET with the most benign behavior [28]. However, in recent years it has become clear that gastroenteropancreatic NETs, especially foregut NETs, are heterogeneous in their morphological and biological features. In the last two decades efforts were therefore made by the WHO to define NET features that discriminate true benign behavior (low risk) from low-grade malignant well-differentiated NETs in the different parts of the digestive system. Although the new WHO classification is an important step toward defining the diverse tumor biology of NETs, further efforts are necessary to improve the prognostic assessment of the individual NET.

\section{Körner}

Department of Pathology, University of Bern, Bern, Switzerland

\section{J. M. Lopes}

Department of Pathology, Porto Medical School and IPATIMUP, University of Porto,

Porto, Portugal

A.-M. McNicol

Department of Pathology, Glasgow Royal Infirmary, Glasgow, Scotland, UK

O. Nilsson

Department of Pathology, Gothenborg University, Gothenburg, Sweden

A. Perren

Department of Pathology, Universitätsspital Zürich,

Zürich, Switzerland

\section{A. Scarpa}

Department of Pathology, University of Verona, Verona, Italy

J.-Y. Scoazec

Department of Pathology, University of Lyon,

Lyon, France

B. Wiedenmann

Department of Internal Medicine, Campus Virchow Klinikum, Berlin, Germany 
The demand for standards in the stratification and treatment of patients with gastroenteropancreatic NETs prompted the recently established European Neuroendocrine Tumor Society (ENETS) to define guidelines [22, 33]. Such guidelines underwent scrutiny for consensus in the first of two meetings entitled "Consensus Conference on the ENETS Guidelines for the Diagnosis and Treatment of Neuroendocrine Gastrointestinal Tumors, Part 1: Foregut Tumors" held in Frascati (Rome, Italy) from November $2-5,2005$. During this meeting the clinical need for a tumor-node-metastasis (TNM) classification of gastroenteropancreatic NETs was felt. Here we report the TNM staging classification proposal for foregut NETs that was approved at this consensus conference. In addition, we suggest a simple grading system with some pointers that may help to standardize the prognostic assessment of gastroenteropancreatic NETs.

\section{Materials and methods}

Sixty-two experts in the field of digestive endocrine tumors from 20 different countries attended the Consensus Con- ference. The attendees represented all medical branches involved in managing patients with gastroenteropancreatic NETs. They formed four working groups according to their specific clinical expertise: (1) pathology and genetics (11 participants, all listed as authors and G. Klöppel), (2) surgery (10 participants, including the coauthors $\mathrm{H}$. Alhman and M. Falconi), (3) imaging and radiology (10 participants), (4) medicine and clinical pathology (31 participants, including the coauthors M. Caplin, W.W. de Herder, B. Erikssson, and B. Wiedenmann).

The Conference was divided sequentially into eight sessions devoted to specific topics on an anatomical basis (gastric NET sessions 1-2, duodenal NET, pancreatic NET sessions $1-4$, and poorly differentiated endocrine carcinomas). A working booklet with the ENETS guidelines and specific queries had been prepared in advance by the Organizing Committee. The work was organized such that, after a short case presentation in a plenary session, each working group gathered separately to discuss groupspecific questions. Once agreement was reached within each group, consensus statements were discussed and approved or rejected by all participants gathered in the plenary session. This procedure was followed for all eight sessions. The TNM staging proposal was made by the

Table 1 Proposal for a TNM classification and disease staging for gastric endocrine tumors

\begin{tabular}{|c|c|c|c|}
\hline \multicolumn{4}{|l|}{ TNM } \\
\hline \multicolumn{4}{|c|}{$\mathrm{T}$-primary tumor } \\
\hline $\mathrm{TX}$ & \multicolumn{3}{|c|}{ Primary tumor cannot be assessed } \\
\hline T0 & \multicolumn{3}{|c|}{ No evidence of primary tumor } \\
\hline Tis & \multicolumn{3}{|c|}{ In situ tumor/dysplasia $(<0.5 \mathrm{~mm})$} \\
\hline $\mathrm{T} 1$ & \multicolumn{3}{|c|}{ Tumor invades lamina propria or submucosa and $\leq 1 \mathrm{~cm}$} \\
\hline $\mathrm{T} 2$ & \multicolumn{3}{|c|}{ Tumor invades muscularis propria or subserosa or $>1 \mathrm{~cm}$} \\
\hline $\mathrm{T} 3$ & \multicolumn{3}{|c|}{ Tumor penetrates serosa } \\
\hline $\mathrm{T} 4$ & \multicolumn{3}{|c|}{ Tumor invades adjacent structures } \\
\hline & \multicolumn{3}{|c|}{ For any $\mathrm{T}$, add $(\mathrm{m})$ for multiple tumors } \\
\hline \multicolumn{4}{|c|}{$\mathrm{N}$-regional lymph nodes } \\
\hline NX & \multicolumn{3}{|c|}{ Regional lymph nodes cannot be assessed } \\
\hline No & \multicolumn{3}{|c|}{ No regional lymph node metastasis } \\
\hline N1 & \multicolumn{3}{|c|}{ Regional lymph node metastasis } \\
\hline \multicolumn{4}{|c|}{$\mathrm{M}$-distant metastasis } \\
\hline MX & \multicolumn{3}{|c|}{ Distant metastasis cannot be assessed } \\
\hline M0 & \multicolumn{3}{|c|}{ No distant metastases } \\
\hline $\mathrm{M} 1^{\mathrm{a}}$ & \multicolumn{3}{|c|}{ Distant metastasis } \\
\hline \multicolumn{4}{|l|}{ Stage } \\
\hline \multicolumn{4}{|c|}{ Disease stages } \\
\hline Stage 0 & Tis & N0 & M0 \\
\hline Stage I & $\mathrm{T} 1$ & No & M0 \\
\hline Stage IIa & $\mathrm{T} 2$ & N0 & M0 \\
\hline IIb & $\mathrm{T} 3$ & No & M0 \\
\hline Stage IIIa & $\mathrm{T} 4$ & No & M0 \\
\hline $\mathrm{IIIb}$ & Any $\mathrm{T}$ & $\mathrm{N} 1$ & M0 \\
\hline Stage IV & Any $\mathrm{T}$ & Any N & M1 \\
\hline
\end{tabular}

${ }^{\mathrm{a}} \mathrm{M} 1$ specific sites defined according to Sobin and Wittekind [29] 
Pathology and Genetics working group and amended and approved by the plenary session of the consensus conference. The grading system was discussed and defined by the Pathology and Genetics working group only.

\section{Results and discussion}

The consensus guidelines are reported elsewhere. Here, we report the TNM staging proposal for gastroenteropancreatic NETs of the foregut together with a grading system that may be relevant for the prognostic assessment by the pathologist. The foregut NETs were separated into gastric, duodenal (including ampulla and proximal jejunum), and pancreatic NETs, but were not distinguished according to specific functional activity, main tumor cell type, and specific genetic background.

TNM staging proposal (see Tables 1, 2 and 3)

The currently published TNM format was adopted as working template [29].

Tumor The proposed definition of tumor in situ applies to the stomach only and adheres to the literature [30]. No definition is given for the duodenum and pancreas because none has been agreed upon in spite of recent working proposals [1, 2]. The size limits indicated for $\mathrm{T} 1$ are those defined by the WHO for tumors with "benign behavior" according to site-specific clinicopathological correlations $[5,7,31]$. Similarly, for T2 of the stomach and duodenum, the sizes are those indicated for tumors of "uncertain behavior." In the pancreas the size limit given for T2 needs to be validated [5]. Deeply invasive tumors are included under the T3 and T4 definitions, taking into account sitespecific features.

Nodes N1 indicates the presence of any single or multiple metastases in regional lymph nodes, according to TNM rules. Although the presence of regional lymph-node metastases is, per se, a negative prognostic factor in gastroenteropancreatic NETs [11], the prognostic significance of the number of metastatic nodes is not known. In light of this, stage $3 \mathrm{~B}$ of Tables 1,2 and 3 is proposed to mark the N1 status for future validation.

Distant metastasis M1 indicates the presence of any single or multiple metastases at any distant anatomical site (including nonregional nodes). Because there is evidence that extrahepatic bone metastases are a particularly ominous

Table 2 Proposal for a TNM classification and disease staging for endocrine tumors of the duodenum/ampulla/proximal jejunum

\section{TNM}

T-primary tumor

TX

T0

$\mathrm{T} 1$

$\mathrm{T} 2$

T3

$\mathrm{T} 4$

$\mathrm{N}-$ regional lymph nodes

NX

N0

N1

$\mathrm{M}$-distant metastases

MX

M0

$\mathrm{M} 1^{\mathrm{b}}$

Stage

Disease stages

Stage I T1

Stage IIa T2

IIb $\quad \mathrm{T} 3$

Stage IIIa T4

IIIb Any T

Stage IV
Primary tumor cannot be assessed

No evidence of primary tumor

Tumor invades lamina propria or submucosa and size $\leq 1 \mathrm{~cm}^{\mathrm{a}}$

Tumor invades muscularis propria or size $>1 \mathrm{~cm}$

Tumor invades pancreas or retroperitoneum

Tumor invades peritoneum or other organs

For any $\mathrm{T}$, add $(\mathrm{m})$ for multiple tumors

Regional lymph nodes cannot be assessed

No regional lymph node metastasis

Regional lymph node metastasis

Distant metastasis cannot be assessed

No distant metastases

Distant metastasis
N0 $\quad$ M0

N0 M0

N0 $\quad$ M0

N0 M0

N1 M0

Any N M1

${ }^{a}$ Tumor limited to ampulla of Vater for ampullary gangliocytic paraganglioma

${ }^{b}$ M1 specific sites defined according to Sobin and Wittekind [29] 
Table 3 Proposal for a TNM classification and disease staging for endocrine tumors of the pancreas

\begin{tabular}{|c|c|c|c|}
\hline \multicolumn{4}{|l|}{ TNM } \\
\hline \multicolumn{4}{|c|}{$\mathrm{T}$-primary tumor } \\
\hline $\mathrm{TX}$ & \multicolumn{3}{|c|}{ Primary tumor cannot be assessed } \\
\hline T0 & \multicolumn{3}{|c|}{ No evidence of primary tumor } \\
\hline $\mathrm{T} 1$ & \multicolumn{3}{|c|}{ Tumor limited to the pancreas and size $<2 \mathrm{~cm}$} \\
\hline $\mathrm{T} 2$ & \multicolumn{3}{|c|}{ Tumor limited to the pancreas and size $2-4 \mathrm{~cm}$} \\
\hline $\mathrm{T} 3$ & \multicolumn{3}{|c|}{ Tumor limited to the pancreas and size $>4 \mathrm{~cm}$ or invading duodenum or bile duct } \\
\hline $\mathrm{T} 4$ & $\begin{array}{l}\text { Tumor } \\
\text { or the } \\
\text { For any }\end{array}$ & $\begin{array}{l}\text { spleen, cc } \\
\text { superior } 1\end{array}$ & \\
\hline \multicolumn{4}{|c|}{$\mathrm{N}$-regional lymph nodes } \\
\hline NX & \multicolumn{3}{|c|}{ Regional lymph node cannot be assessed } \\
\hline No & \multicolumn{3}{|c|}{ No regional lymph node metastasis } \\
\hline N1 & \multicolumn{3}{|c|}{ Regional lymph node metastasis } \\
\hline \multicolumn{4}{|c|}{$\mathrm{M}$-distant metastases } \\
\hline MX & \multicolumn{3}{|c|}{ Distant metastasis cannot be assessed } \\
\hline M0 & \multicolumn{3}{|c|}{ No distant metastases } \\
\hline$M 1^{\mathrm{a}}$ & \multicolumn{3}{|c|}{ Distant metastasis } \\
\hline \multicolumn{4}{|l|}{ Stage } \\
\hline \multicolumn{4}{|c|}{ Disease stages } \\
\hline Stage I & $\mathrm{T} 1$ & No & M0 \\
\hline Stage IIa & $\mathrm{T} 2$ & No & M0 \\
\hline $\mathrm{IIb}$ & $\mathrm{T} 3$ & No & M0 \\
\hline Stage IIIa & $\mathrm{T} 4$ & No & M0 \\
\hline $\mathrm{IIIb}$ & Any $\mathrm{T}$ & N1 & M0 \\
\hline Stage IV & Any $\mathrm{T}$ & Any N & M1 \\
\hline
\end{tabular}

${ }^{a}$ M1 specific sites defined according to Sobin and Wittekind [29]

sign $[6,20]$, it is recommended to specify the anatomical site of the metastasis according to the TNM classification rules (PUL, pulmonary; HEP, hepatic; OSS, osseous; etc.) [29].

Staging The proposed staging system lists stage 0 only for the stomach because this is the only anatomical site where Tis is defined. Stage I encompasses the T1 NETs with limited growth. Stage II identifies tumors that are larger in size or more invasive, either T2 or T3, though always in the absence of metastasis. At stage III the increased malignancy refers either to invasion into surrounding structures (stage IIIa) or to the presence of regional node metastasis (stage IIIb). Stage IV always implies the presence of distant metastasis.

Table 4 Grading proposal for foregut (neuro)endocrine tumors

\begin{tabular}{lll}
\hline Grade & Mitotic count $(10 \mathrm{HPF})^{\mathrm{a}}$ & Ki-67 index $(\%)^{\mathrm{b}}$ \\
\hline G1 & $<2$ & $\leq 2$ \\
G2 & $2-20$ & $3-20$ \\
G3 & $>20$ & $>20$ \\
\hline
\end{tabular}

${ }^{\mathrm{a}} 10 \mathrm{HPF}$ : high power field $=2 \mathrm{~mm}^{2}$, at least 40 fields (at $40 \times$ magnification) evaluated in areas of highest mitotic density

${ }^{b}$ MIB1 antibody; \% of 2,000 tumor cells in areas of highest nuclear labeling
Grading proposal (see Table 4)

Grading It has been widely discussed and generally accepted that no histological grading system effectively predicts the behavior of well-differentiated endocrine tumors. The major obstacle to developing a practically effective grading system is the fact that severe cytological atypia, as, for instance, in pheochromocytomas, has no impact on the clinical behavior and malignancy of such tumors. However, recent studies in well differentiated NETs of the foregut, including the pancreas, and of the midgut have shown the usefulness of a grading system [10, 25, 32]. Thus, well-differentiated endocrine tumors with a more solid appearance and distinct proliferative activity, which also lead to difficulties in the differential diagnosis vs poorly differentiated endocrine carcinomas, seem to have a worse prognosis than NETs without these features [16-18, $22,23]$. It was therefore decided to introduce a grading system that could be of help in distinguishing the welldifferentiated NETs into G1 and G2 categories.

As a working suggestion, we propose to apply to foregut NETs a grading system modified from that adopted by the WHO for endocrine tumors of the lung, though exclusively referring to the proliferation status. In brief (see Table 4), three tumor categories are identified: $\mathrm{G} 1,<2$ mitosis per 
$2 \mathrm{~mm}^{2}$ [10 high power fields (HPF) $40 \times$ magnification] and/or Ki-67 index $\leq 2 \%$; G2, 2-20 mitosis per $2 \mathrm{~mm}^{2}$ and/or Ki-67 index between 3 and 20\%; G3 with 21 or more mitosis per $2 \mathrm{~mm}^{2}$ and $\mathrm{Ki}-67$ index $>20 \%$.

In general, G1 and G2 should refer to well-differentiated NETs displaying diffuse and intense expression of the two general immunohistochemical neuroendocrine markers, chromogranin A and synaptophysin [26]. Punctate necrosis is, per se, indicative of a more aggressive tumor, pointing to a G2 status, which, however, has to be confirmed by the mitotic count. G3 indicates a poorly differentiated neuroendocrine carcinoma. It has high mitotic counts/Ki-67 index, is often associated with fields of necrosis, and shows significantly reduced chromogranin A expression, while maintaining intense staining for synaptophysin. It is relevant to remind here that the diagnosis of G3 carcinoma is based on a specific histologic pattern according to the current WHO criteria [5, 7, 31]. In addition, the clinical behavior of G3 poorly differentiated neuroendocrine carcinomas of the gastroenteropancreatic tract does not necessarily correspond to that of small cell cancers of the lung or of any other sites.

Mitotic count and Ki-67 index We propose that mitoses should be counted on hematoxylin and eosin-stained slides in at least $40 \mathrm{HPFs}$, where possible. The mitoses should be assessed in areas where they are most frequent after a general slide survey. For Ki-67 assessment, the MIB1 antibody is recommended at the conditions that have been established at the laboratory in question. The Ki-67 index should be assessed in 2,000 tumor cells in areas where the highest nuclear labeling is observed (often but not exclusively at the tumor periphery).

\section{Concluding remarks}

Requests for standardization in the management of patients with gastroenteropancreatic NETs recently resulted in the development of several guidelines, including those proposed by ENETS [16, 17, 22, 23]. However, it was never attempted to reach consensus on specific practical issues. The TNM staging system we propose here was developed to meet a clinical need, is based on the current WHO classifications of endocrine and digestive tumors, and is the result of a consensus conference held by specialists involved in the management of digestive endocrine tumor patients. Along the same line, the grading system described here attempts to close the gap between the advances of the most recent WHO classifications and the need for a better prognostic assessment of NETs. It is obvious, of course, that all our proposals have to be validated by future clinicopathological work.

Acknowledgements Support came from grants from Ministry for Instruction University and Research (COFIN 2005) and the University of Parma to G. Rindi. The meeting in Frascati was supported by a generous grant to ENETS from IPSEN Pharmaceutical.

\section{References}

1. Anlauf M, Perren A, Meyer CL, Schmid S, Saremaslani P, Kruse ML, Weihe E, Komminoth P, Heitz PU, Klöppel G (2005) Precursor lesions in patients with multiple endocrine neoplasia type 1-associated duodenal gastrinomas. Gastroenterology 128:1187-1198

2. Anlauf M, Wieben D, Perren A, Sipos B, Komminoth P, Raffel A, Kruse ML, Fottner C, Knoefel WT, Monig H, Heitz PU, Klöppel G (2005) Persistent hyperinsulinemic hypoglycemia in 15 adults with diffuse nesidioblastosis: diagnostic criteria, incidence, and characterization of beta-cell changes. Am J Surg Pathol 29:524-533

3. Artale S, Giannetta L, Cerea G, Pedrazzoli P, Schiavetto I, Napolitano M, Veronese S, Bramerio E, Gambacorta M, Vanzulli A, Pisconti S, Pugliese R, Siena S (2005) Treatment of metastatic neuroendocrine carcinomas based on WHO classification. Anticancer Res 25:4463-4469

4. Bajetta E, Catena L, Procopio G, Bichisao E, Ferrari L, Della Torre S, De Dosso S, Iacobelli S, Buzzoni R, Mariani L, Rosai J (2005) Is the new WHO classification of neuroendocrine tumours useful for selecting an appropriate treatment? Ann Oncol 16:1374-1380

5. DeLellis RA, Lloyd RV, Heitz PU, Eng C (eds) (2004) World Health Organization classification of tumours, pathology and genetics of tumours of endocrine organs. IARC, Lyon

6. Gibril F, Doppman JL, Reynolds JC, Chen CC, Sutliff VE, Yu F, Serrano J, Venzon DJ, Jensen RT (1998) Bone metastases in patients with gastrinomas: a prospective study of bone scanning, somatostatin receptor scanning, and magnetic resonance image in their detection, frequency, location, and effect of their detection on management. J Clin Oncol 16:1040-1053

7. Hamilton SR, Aaltonen LA (eds) (2000) World Health Organization classification of tumours, pathology and genetics of tumours of the digestive system. IARC, Lyon

8. Hemminki K, Li X (2001) Familial carcinoid tumors and subsequent cancers: a nation-wide epidemiologic study from Sweden. Int J Cancer 94:444-448

9. Hemminki K, Li X (2001) Incidence trends and risk factors of carcinoid tumors: a nationwide epidemiologic study from Sweden. Cancer 92:2204-2210

10. Hochwald SN, Zee S, Conlon KC, Colleoni R, Louie O, Brennan MF, Klimstra DS (2002) Prognostic factors in pancreatic endocrine neoplasms: an analysis of 136 cases with a proposal for low-grade and intermediate-grade groups. J Clin Oncol 20:2633-2642

11. Jensen RT (1999) Natural history of digestive endocrine tumors. In: Mignon $\mathrm{M}$, Colombel $\mathrm{JF}$ (eds) Recent advances in the pathophysiology and management of inflammatory bowel diseases and digestive endocrine tumors. John Libbey Eurotext, Montrouge, pp 192-219

12. Maggard MA, O'Connell JB, Ko CY (2004) Updated populationbased review of carcinoid tumors. Ann Surg 240:117-122 
13. Modlin IM, Kidd M, Latich I, Zikusoka MN, Shapiro MD (2005) Current status of gastrointestinal carcinoids. Gastroenterology 128:1717-1751

14. Modlin IM, Lye KD, Kidd M (2003) A 5-decade analysis of 13,715 carcinoid tumors. Cancer 97:934-959

15. Öberendorfer S (1907) Karzinoide tumoren des Dünndarms. Frankf Z Pathol 1:426-432

16. Oberg K, Astrup L, Eriksson B, Falkmer SE, Falkmer UG, Gustafsen J, Haglund C, Knigge U, Vatn MH, Valimaki M (2004) Guidelines for the management of gastroenteropancreatic neuroendocrine tumours (including bronchopulmonary and thymic neoplasms). Part I-general overview. Acta Oncol 43:617-625

17. Oberg K, Astrup L, Eriksson B, Falkmer SE, Falkmer UG, Gustafsen J, Haglund C, Knigge U, Vatn MH, Valimaki M (2004) Guidelines for the management of gastroenteropancreatic neuroendocrine tumours (including bronchopulmonary and thymic neoplasms). Part II—specific NE tumour types. Acta Oncol 43: 626-636

18. Oberg K, Kvols L, Caplin M, Delle Fave G, de Herder W, Rindi G, Ruszniewski P, Woltering EA, Wiedenmann B (2004) Consensus report on the use of somatostatin analogs for the management of neuroendocrine tumors of the gastroenteropancreatic system. Ann Oncol 15:966-973

19. Panzuto F, Di Fonzo M, Iannicelli E, Sciuto R, Maini CL, Capurso G, Milione M, Cattaruzza MS, Falconi M, David V, Ziparo V, Pederzoli P, Bordi C, Delle Fave G (2006) Long-term clinical outcome of somatostatin analogues for treatment of progressive, metastatic, well-differentiated entero-pancreatic endocrine carcinoma. Ann Oncol 17:461-466

20. Panzuto F, Nasoni S, Falconi M, Corleto VD, Capurso G, Cassetta S, Di Fonzo M, Tornatore V, Milione M, Angeletti S, Cattaruzza MS, Ziparo V, Bordi C, Pederzoli P, Delle Fave G (2005) Prognostic factors and survival in endocrine tumor patients: comparison between gastrointestinal and pancreatic localization. Endocr Relat Cancer 12:1083-1092

21. Pelosi G, Bresaola E, Bogina G, Pasini F, Rodella S, Castelli P, Iacono C, Serio G, Zamboni G (1996) Endocrine tumors of the pancreas: Ki-67 immunoreactivity on paraffin sections is an independent predictor for malignancy: a comparative study with proliferating-cell nuclear antigen and progesterone receptor protein immunostaining, mitotic index, and other clinicopathologic variables. Hum Pathol 27:1124-1134

22. Plöckinger U, Rindi G, Arnold R, Eriksson B, Krenning EP, de Herder WW, Goede A, Caplin M, Oberg K, Reubi JC, Nilsson O, Delle Fave G, Ruszniewski P, Ahlman H, Wiedenmann B (2004) Guidelines for the diagnosis and treatment of neuroendocrine gastrointestinal tumours. A consensus statement on behalf of the European Neuroendocrine Tumour Society (ENETS). Neuroendocrinology 80:394-424

23. Ramage JK, Davies AH, Ardill J, Bax N, Caplin M, Grossman A, Hawkins R, McNicol AM, Reed N, Sutton R, Thakker R, Aylwin $\mathrm{S}$, Breen D, Britton K, Buchanan K, Corrie P, Gillams A, Lewington V, McCance D, Meeran K, Watkinson A (2005) Guidelines for the management of gastroenteropancreatic neuroendocrine (including carcinoid) tumours. Gut 54(Suppl 4):iv1-iv16

24. Rigaud G, Missiaglia E, Moore PS, Zamboni G, Falconi M, Talamini G, Pesci A, Baron A, Lissandrini D, Rindi G, Grigolato P, Pederzoli P, Scarpa A (2001) High resolution allelotype of nonfunctional pancreatic endocrine tumors: identification of two molecular subgroups with clinical implications. Cancer Res 61:285-292

25. Rindi G, Azzoni C, La Rosa S, Klersy C, Paolotti D, Rappel S, Stolte M, Capella C, Bordi C, Solcia E (1999) ECL cell tumor and poorly differentiated endocrine carcinoma of the stomach: prognostic evaluation by pathological analysis. Gastroenterology 116:532-542

26. Rindi G, Villanacci V, Ubiali A (2000) Biological and molecular aspects of gastroenteropancreatic neuroendocrine tumors. Digestion 45:19-26

27. Ruszniewski P, Ish-Shalom S, Wymenga M, O'Toole D, Arnold R, Tomassetti P, Bax N, Caplin M, Eriksson B, Glaser B, Ducreux M, Lombard-Bohas C, de Herder WW, Delle Fave G, Reed N, Seitz JF, Van Cutsem E, Grossman A, Rougier P, Schmidt W, Wiedenmann B (2004) Rapid and sustained relief from the symptoms of carcinoid syndrome: results from an open 6-month study of the 28-day prolonged-release formulation of lanreotide. Neuroendocrinology 80:244-251

28. Sandor A, Modlin IM (1998) A retrospective analysis of 1570 appendiceal carcinoids. Am J Gastroenterol 93:422-428

29. Sobin LH, Wittekind C (eds) (2002) TNM classification of malignant tumours. Wiley-Liss, New York

30. Solcia E, Bordi C, Creutzfeldt W, Dayal Y, Dayan AD, Fålkmer S, Grimelius L, Havu N (1988) Histopathological classification of nonantral gastric endocrine growths in man. Digestion 41:185-200

31. Solcia E, Klöppel G, Sobin LH (2000) Histological typing of endocrine tumours. Springer, Berlin Heidelberg New York

32. Van Eeden S, Quaedvlieg PF, Taal BG, Offerhaus GJ, Lamers CB, Van Velthuysen ML (2002) Classification of low-grade neuroendocrine tumors of midgut and unknown origin. Hum Pathol 33:1126-1132

33. Wiedenmann B (2004) From ENET to ENETS: a long odyssey in the land of small and rare tumors. Neuroendocrinology 80:1-12 